\title{
Establishing Circular Plot Boundaries With a Wedge Prism and an Adjustable Target Pole
}

\author{
W. ELTON WHITE AND CLIFFORD E. LEWIS
}

\section{Abstract}

A target pole used with a wed ge prism to establish a one-size circular plot has been modified so that one target pole and prism can be used to establish the perimeter of circular plots of different sizes by a simple adjustment.

Authors are forestry research technician and principal range scient ist, Southeastern Forest Exp. Sta., Forest Serv., U.S. Dep. Agr., Marianna, Fla. 32446. Manuscript received June $16,1980$.
If you use circular plots of various sizes for sampling vegetation, you will be interested in a method that worked well for us. Establishing the perimeters of circular plots in shrubby or forested vegetation can be very time consuming because of the need to return to the plot center repeatedly to measure out to the perimeter, and sampling techniques sometimes require plots of increasingly larger size to be located around a central point in order to sample the various vegetation components such as herbage, shrubs, and trees. 
Table 1. Dimensions for establishing circular plots of various sizes when using an exact (3.03 dioptor) BAF-10 wedge prism.

\begin{tabular}{ccc}
\hline $\begin{array}{c}\text { Plot size } \\
\text { (acres) }\end{array}$ & $\begin{array}{c}\text { Plot radius } \\
\text { (feet) }\end{array}$ & $\begin{array}{c}\text { Target width' } \\
\text { (inches) }\end{array}$ \\
\hline $1 / 2$ & 83.3 & 30.3 \\
$1 / 4$ & 58.9 & 21.4 \\
$1 / 5$ & 52.7 & 19.2 \\
$1 / 10$ & 37.2 & 13.5 \\
$1 / 20$ & 26.3 & 9.6 \\
$1 / 40$ & 18.6 & 6.8 \\
\hline
\end{tabular}

IDistance between the top of the red band and the top of the blue band.

Nyland and Remele (1975) described a method for establishing circular plots by using a center target pole and a wedge prism with a basal area factor of 10 (BAF-10). Their target pole was designed to establish only a one-size circular plot. Recently, Korhonen (1979) discussed a theory for using prisms of various factors; he also suggested a technique for using the target pole to establish plots of different sizes by mounting tin cans on a wooden staff to serve as the target. Additional screw holes allowed the cans to be moved to establish different plot sizes.

To easily vary circular plot sizes and to allow easy reading of the target pole, we modified the Nyland and Remele method and made an adjustable target pole which is readily discernible in rather dense forests.

The Nyland and Remele target pole was made from 1.5-inchdiameter dowel that was 4.5 feet long with a spike in the bottom. The pole was painted white with a red band a few inches from the top and a blue band painted a specified distance below the red one. When the pole is viewed from the correct distance (plot perimeter) through a prism with the thin edge at the top, the blue band is superimposed exactly on the red band. We found this pole to be too small in diameter and too short for easy viewing in the longleafslash pine forests of the South, especially when establishing 1/4and $1 / 2$-acre plots.

To use one target pole to establish plots of different sizes, we modified their pole by making the blue band movable. To correct the size of the pole, we had to find material that was light enough to carry over long distances. A piece of white plastic drainpipe, 4 inches in diameter and thin walled, proved to be ideal. A 6-foot section with a metal spike bolted to one end for securing the pipe to the ground was constructed (Fig. 1). A 2-inch-wide red band was painted 3 inches from the top of the pipe. For a blue band, we laminated a 2-inch-wide piece of blue paper in plastic to make it waterproof. The laminated band was placed around the pipe with the ends overlapping and just loose enough so that the band could be moved; then the band was connected with clear, plastic adhesive tape. A thin, permanent line was marked around the pole at each target width that is the correct distance below the red band for locating the blue band to identify the different plot sizes.

Target width, or the distance between the red and blue bands, and BAF of the wedge prism are critical factors in the prism-plot technique. If the prism is an "exact" BAF-10, the target width (in inches) is determined by dividing the plot radius (in feet) by 2.75 (Table 1). For metric-size plots, the target width (in centimeters) is determined by dividing the plot radius (in meters) by 0.33 . However, most prisms are not "exact"; therefore, the location of the blue band should be checked, or determined, by measuring the distance of the plot radius from the pole for the various plot sizes. When the red and blue band are perfectly aligned while looking

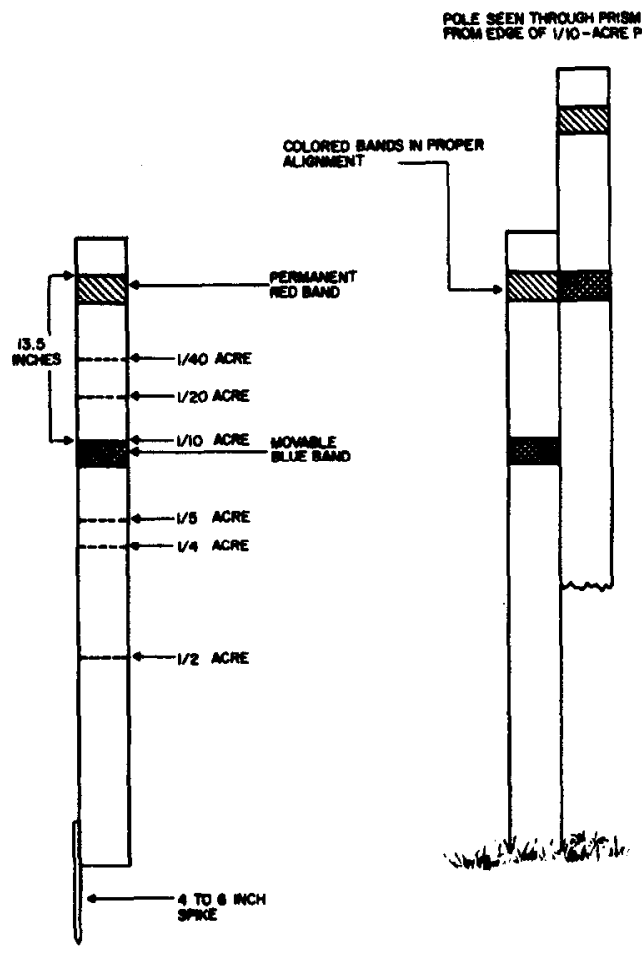

Fig. 1. Diagram of a target pole with an adjustable band, and how it is used with a prism to establish plots.

through the prism (thin edge up), mark the pole for location of the blue band for that particular plot size.

Field use proved the movable blue band to be very satisfactory; it required only a couple of seconds to move it from one plot size to another. We found that one man using the prism-plot technique and a small tape recorder could rapidly gather data in the field. Also, with the added height of the new pole, the blue band was not obscured by vegetation even on the 1/2-acre plots. The greater diameter of the plastic pipe made it possible to easily align the bands with the prism from the distance required for the larger plots. In "borderline" situations, to determine whether a plant is in or out of the plot, it must be remembered that the "exact"center of the plot is 2 inches less than the prism location at the perimeter.

We consider the plastic drainpipe with sliding band to be superior to the Nyland and Remele method because the plot size can be adjusted easily. Also, carrying this pipe through the woods is simple because there is nothing to catch on the vegetation as there would be if cans were used as Korhonen suggested.

Scientists and resource managers frequently need to make vegetation measurements where circular plots are more convenient than rectangular plots. An adjustable target pole makes the prismplot technique adaptable to many situations, and can serve for measuring linear distances as well as for determining boundaries of circular plots.

\section{Literature Cited}

Korhonen, J. 1979. One-person circular plot establishment. Forest Chron. 55:51-53.

Nyland, Ralph D., and Kermit E. Remele. 1975. Prism measures distance for plot boundaries. State Univ. N.Y. Appl. Forest Res. Inst. Res. Note 17. 4 p. 